\title{
A Situated and Embodied Approach to Service Design
}

\author{
Anshuman Saxena \\ Systemic Modeling Laboratory (LAMS) \\ I\&C EPFL, Switzerland \\ anshuman.saxena@epfl.ch
}

\author{
Alain Wegmann \\ Systemic Modeling Laboratory (LAMS) \\ I\&C EPFL, Switzerland \\ alain.wegmann@epfl.ch
}

\begin{abstract}
The two basic questions that every service-designer has to consider are - what features to include in a service, and who all to engage in the implementation of these features? We demonstrate that the true semantics of the value, which a service aims to create for its adopter, resides in the social and bodily being of the adopter. Situating the adopter in her interactions with the external-world helps identify the different responsibilities that the adopter, and other entities occurring in that situation, can undertake in realizing the service. At the same time, embodying the adopter helps acknowledge the role of bodily states in mediating the effect a situation has in terms of the appreciation it invokes at the adopter. We provide a set of four force-dynamic patterns that model this mediation, thereby helping service-designers identify situations that best implement the features required to invoke the desired appreciation.
\end{abstract}

\section{Introduction}

Service is defined as "the application of specialized competences for the benefit of [the adopter]" [1]. The conceptual foundation of services is grounded in the logic of value creation and is referred to as the servicedominant logic of problem-solving [2]. As opposed to the traditional approach to problem-solving, which limits the scope of the solution to the interactions exhibited in the problem situation, the mandate for services is to go deeper and focus on the value that the service creates for the entities constituting the problem situation. The shift from problem-solution to valuecreation highlights the extended life cycle of services, which includes both the supply and consumption phase of the solution. An important tenet of service-dominant logic is the co-creation principle, which stipulates that adopters undertake both supplier and consumer roles during the lifecycle of the service. One popular explanation to justify this duality of customer-supplier -roles is that, at the very least, adopters undertake the role of suppliers by virtue of them providing their bodies, minds, belongings or information as ports through which they consume the service [3]. These ports are points of experience [4], in the sense that experience is the true expression of a customer's desire and that value creation should focus on invoking a desired experience [5]. From a service-design perspective, the artifact that implements the service is called a service system. As defined in [6], service systems are configurations of people, technology, and other resources that co-create value. An important challenge that co-creation presents in identifying service systems is the need to model the different roles that the stakeholders of the service undertake [7].

For example, consider the use of foldable-bike as part of a mixed-mode commuting service. Mixed-mode commute refers to the use of two or more modes of transport for regular travel between home and place of work. Foldable-bike refers to bike designs, which have a collapsible frame, whereby when not in use their form-factor can be reduced to a shape and size of a conventional luggage allowed on board most public transports. For ease of exposition, we restrict the interpretation of mixed-mode transport to the combination of bike and train. In this case, it is relatively evident that the adopter of the mixed-mode commuting service acts as the co-creator of this service by undertaking the supplier-roles of bike-rider and train-passenger. The value that this service may offer to the adopter includes, get to office on time, avoid inconvenience to passengers, save money and reduce health problems. Each of these value-propositions hints at a distinct consumer-role that the adopter undertakes,

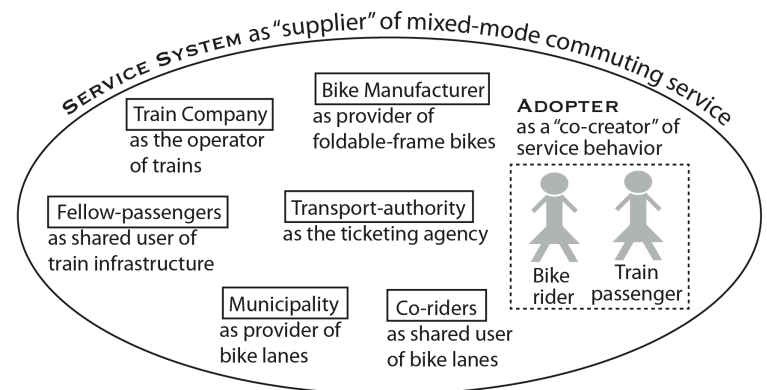

Figure 1: The mixed-mode commuting service system 


\begin{tabular}{|c|c|c|c|c|c|}
\hline \multirow{4}{*}{ 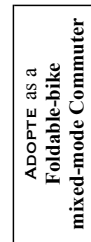 } & $\begin{array}{l}\mathrm{F}_{\mathrm{F}} \text { : Ability to avoid traffic } \\
\text { delays }\end{array}$ & $\mathrm{x}$ & & & \\
\hline & $\begin{array}{l}\begin{array}{l}F_{2}: \text { Ability to avoid travel } \\
\text { with oversized objects }\end{array} \\
\end{array}$ & & $\mathrm{x}$ & & \\
\hline & $\begin{array}{l}F_{3}: \text { Ability to reduce cost } \\
\text { of travel }\end{array}$ & & & $\mathrm{x}$ & \\
\hline & $\begin{array}{l}\mathrm{F}_{4} \text { : Ability to perform } \\
\text { physical workout }\end{array}$ & & & & $\mathrm{x}$ \\
\hline & \multirow[t]{2}{*}{ 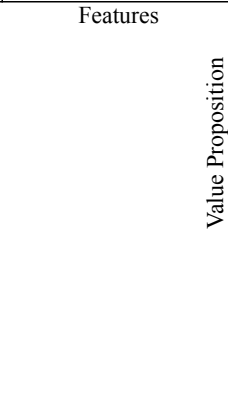 } & 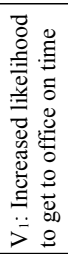 & 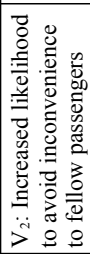 & 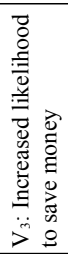 & 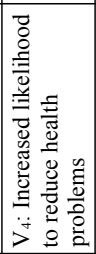 \\
\hline & & 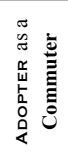 & 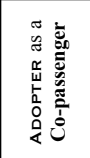 & 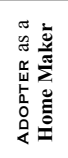 & 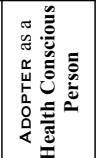 \\
\hline
\end{tabular}

Figure 2: Feature-value matrix for mixed-mode commuting service

namely the roles of commuter, co-passenger, homemaker and health-conscious-person.

The question that arises is, why are roles so important to specifying the service? Roles are important because they reveal the semantics of an entity's participation to a situation. Roles are not assigned in isolation. Identifying the role an entity undertakes requires service-designers to critically reflect on the situation that is invoked while analyzing the adopter's interaction with the world. Situations are contextualized interpretations of the interactions of the participating entities [8]. Thinking in terms of situation helps to identify additional entities that are required to specify the service system. The situation that assigns the supplier-roles of bike-rider and train-passenger also reveal other entities like bike-manufacturer (as provider of bike), municipality (as provider of bike lanes), co-riders (as shared user of bike lanes), traincompany (as the operator of trains), fellow-passengers (as shared user of train infrastructure), and transportauthority (as the ticketing agency). As depicted in Figure 1, all the above-mentioned entities, in their respective roles, together constitute the service system that implements the behavior of the mixed-mode commuting service.

The adoption of this service augments the competence of the adopter by her becoming a mixedmode commuter. Some of the features of the mixedmode-commute-competence include the ability to avoid traffic delays, ability to avoid travel with oversized objects, ability to reduce cost of travel, and the ability to perform physical workout. A mapping between the features of the competence that the adopter acquires by virtue of adopting the service, and the value that this competence creates for the adopter's

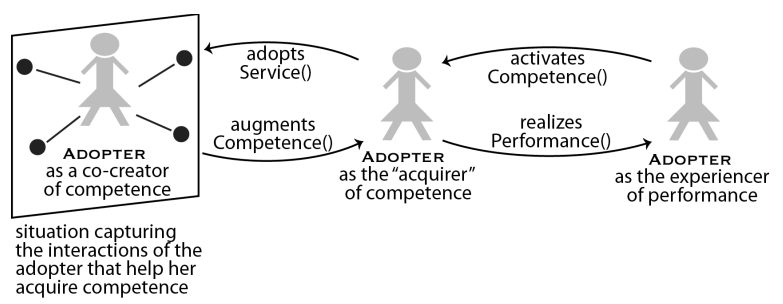

Figure 3: The three-level ontology of service design

larger being is presented as a feature-value matrix in Figure 2.

This raises another question: how can a service designer identify situations that are relevant to the design of the service? For example, how do we reason what features should the service implement, and, thus, which interactions of the adopter with the world should the service focus to change. It is important to note that for the service to be effective, the supplier-roles should be aligned with the consumer roles. The competence that the service creates for the adopter should be one that helps the adopter realize desired experience. The situation that assigns the adopter a consumer role does so by virtue of the adopter's interaction with other entities. These entities enable the performance of the competence in a way that it invokes the desired experience. Figure 3 provides a visual depiction of the conceptual model of service design as an alignment between a competence-creating situation and a competence-experiencing situation.

To illustrate this alignment view of service-design, lets undertake a revision of the earlier discussed mixed-mode commuting service. The revised version is referred to as the mixed-mode commuting+ service. Consider two new value-propositions of this service 'fast-track career progression' and 'greater social recognition'. Unlike the value-propositions of the original service, which were more objective in their value claims - in terms of referring to an observable state change like the change of arriving at the office on time, the change of carrying on-board form-compliant objects, the change of increased savings, and the change of exhibiting better vital signs during medical examination, the new value propositions of the revised service are more affective in nature. The new valuepropositions were specifically chosen to highlight the deeper semantics of value-propositions, one that go beyond observable state change and reside in the consumer's affective judgments of appreciation of the service [9]. The true semantics of appreciation is sticky in nature [10]. It is internal to the adopter and may not always reflect itself in the adopter's interactions with the world. In the context of the new service, one interpretation of 'fast-track career progression' could be the desire to overcome the challenge of 'establishing oneself as a punctual employee'. Based 


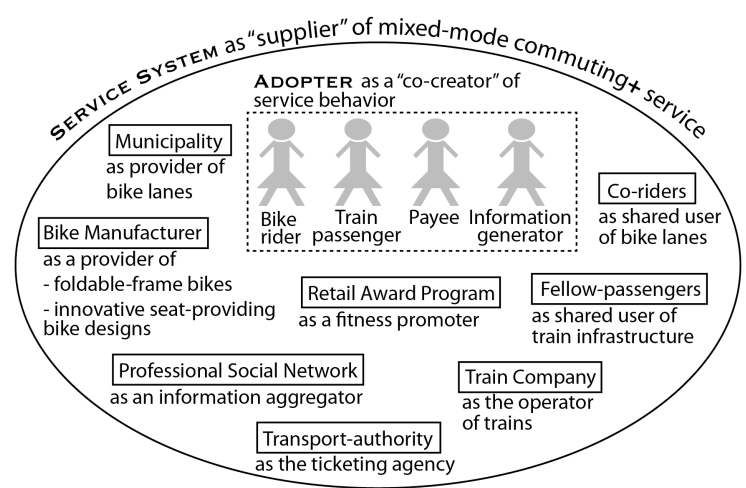

Figure 4: The mixed-mode commuting+ service system

on the underlying situation and the entities revealed therein, one extension to the original service system could be the addition of professional social network site as a supplier that provides automatic update of punctuality profile of the adopter on the web. Similarly, one interpretation of "earn greater social recognition' could be the desire to overcome the challenge of 'reduced social interaction during train travel'. Based on the underlying situation and the entities revealed therein, one extension to the original service system could be the assignment of an addition role to an existing supplier, the bike-manufacturer. In the original version of the service, the bike manufacturer as a supplier was undertaking the role of a foldable-frame-bike manufacturer. The extended version of the service, assigns an additional supplierrole to the bike manufacturer - the role of an innovative designer, which designs bike in a way that enhances the possibility of social interaction, e.g., a bike design that folds to create shared seating space for two will help adopters have guaranteed seating with a friend. The service system for the extended service is depicted in Figure 4. Some additional entities and roles are also included in this service system such as, the retail award program, and the payee and information generator roles of the adopter. These will be explained later when a larger set of value propositions will be discussed as part of the overall illustration of the method proposed in this paper.

This paper addresses the two central questions that every service scientist encounters. First, what should be the features of the service? Second, which entities are required to implement these features? In doing so, we take an experience-design based approach, [11], to service systems modeling. We define service-value as the change the adopter experiences. By experience we mean the adopter's cognitive act of appreciating the service [9]. Cognition is a grounded phenomenon [12], and to understand the cause-and-effects underlying the adopter's appreciation of the service requires attention to the adopter's bodily states and situated actions. The basic idea we propose in this paper is to model an adopter both as a bodily being and a social being. We do so by employing the notions of embodiment and situatedness.

Situatedness refers to the inter-connectedness of the entities observed in a situation by virtue of which the entities exhibit a behavior that cannot be construed from any subset of these entities [13]. The primary challenge in identifying the different roles played by the adopter is in identifying the causal relevance of the entity to the situation in which they occur. At a basic level of conceptualization [14], i.e. the default level of abstraction at which one tends to categorize objects with minimal cognitive effort, the causal relevance of an observed category can be historically inspired, empirically informed, rationally thought, or pragmatically focused [15]. From a service-design perspective, the interest in a given situation is limited to its functional organization, which requires taking an exclusively pragmatic view of the world. We activate the semantics of situatedness by modeling situations in terms of the image they invoke. An image-oriented conceptualization, [16], of the situation will help the service scientist reason the epistemic groundings of the observed entities by drawing parallels with more widely shared aspects of visual perception such as, form-oriented roles of gestalt completion, including background-foreground, cognitive reference and baseprofile [17]. Requiring service scientists to make explicit their interpretation of the conceptual relevance of the entity observed in a situation will help them specify more clearly the responsibilities that the observed entity should undertake in implementing various aspects of the lifecycle of the service.

Embodiment refers to the bodily states that the human body retains in the memory as internal reference to experiences from past situations [18]. For example, the stretching of facial muscles in a certain way that constitutes a smile (the smiling musculature) is a common embodiment for situations that invoke pleasant experiences. Researchers have shown that even if the smiling musculature is engaged in a different setting say, holding a pencil in the mouth in a certain way, it still invokes a positive affect in the experiencer [19]. An embodied approach to service design acknowledges the significance of previously acquired bodily states in invoking judgments of appreciation. As suggested in [20], we see embodiment as a "pattern-completion inference mechanism" that completes a cause-and-effect pattern by revealing the effect (the appreciative judgment) when provided with the cause (the situation), and by revealing the cause (the situation) when provided with the effect (the appreciative judgment), Figure 5. In the case of smiling, the appreciative judgment is the feeling of happiness, and the situation is holding a pencil in the 


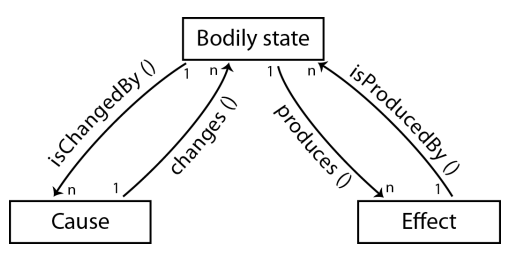

Figure 5: Embodiment as mediating cause-and-effect

mouth. There can be several situations that invoke the same appreciative judgment, e.g., the smiling musculature can be achieved by holding a pencil in the mouth, eating big-bite size food, undergoing facial therapy, or even community laughter clubs that practice voluntary laughter to feel happy [21].

We employ the semantics of embodiment to activate our proposal of modeling service-value as the change the adopter experiences. By modeling change in terms of bodily states, we ensure the coverage of both types of action-outcomes - ones that bring about observable state change, e.g. on-time arrival, and others that invoke affective judgments of appreciation, e.g. social recognition.

The field of Cognitive Semantics [22-25], which is the study of language from a cognitive perspective, suggests that the meaning of a concept resides in the human conceptual system and cannot be specified in terms of necessary and sufficient conditions that refer to some entity or relation in the real world. The later represents classical theories of semantics such as the work on truth-conditional semantics [26]. An important work in the field of Cognitive Semantics is that of Leonard Talmy who studied the cognitive grounding of the concept of causation and proposed a force-dynamic framework to reason change [27]. Talmy proposes the idea of extended causation, which includes all such dynamics as causative where there is evidence of mutually opposing forces trying to bring about some change in the existing state of affairs.

It is this notion of extended causation that we use to specify bodily states in terms of the forces exerted on the adopter. The insight that this work provides is that in the context of value-oriented problem solving, the nature of the challenge (imposing, blocking, hindering or disrupting) that the solution helps the adopter overcome, and the way it does so (weakening, strengthening, or maintaining), results in four distinct force-dynamic patterns i.e. four types of bodily states.

The change that the adopter experiences could be by virtue of - the adopter correcting its past behavior, the Correction Frame; some partner entity enforcing a certain behavior on the adopter, the Enforcement Frame; the partner entity facilitating the adopter's behavior, the Facilitation Frame; the adopter getting mature to be able to overcome the partner entity's resistance, the Maturity Frame. Frames are attribute-

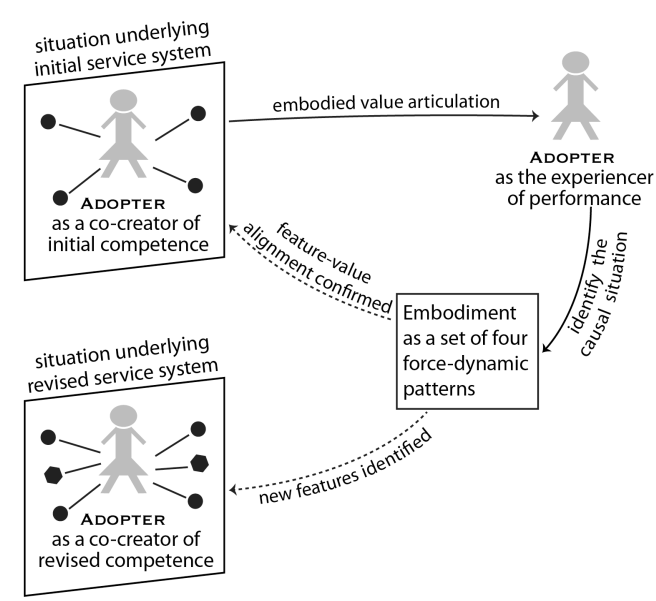

Figure 6: Situated-and-embodied service-design using force-dynamic patterns

value constructs [28], particularly useful for representing knowledge pertaining to coherent regions of conceptual space. In the current context, they help organize the different components of the value concept - the force-dynamic patterns of causal interplay, the resulting change, and the experience thus realized, as one unified piece of information that provides a complete and true picture of the semantics of the value concept. Our claim is that these frames can guide the efforts of the service scientist in identifying the features of the service and the entities required to cocreate them, Figure 6.

Existing service systems design methods acknowledge the subjective nature of the value concept. Nevertheless, in the absence of any systematic approach to characterize value, these methods fail to go beyond propositional considerations, such as the emphasis on the use of modal expressions to highlight the affective judgment of the adopter with regards to the service. Service blueprinting is one design methodology that is widely used for the design of services [29]. Service blueprinting takes a transactional approach to services [30], and helps represent the service as a process diagram that uses the standard visual modeling notations of boxes and arrows to document the different components of the service, and the interaction points through which the consumer interacts with the service. The visual mode of representation makes service blueprinting an effective tool to communicate with the stakeholders, for example in visualizing the quality of experience that the service provides to the customer at different points of interaction. Nevertheless, service blueprinting does not contribute much to the semantics of service systems. It only helps document the customer's response to the service in a way that highlights the specific aspect of the service to which the response pertains. This, undoubtedly, provides a good starting 


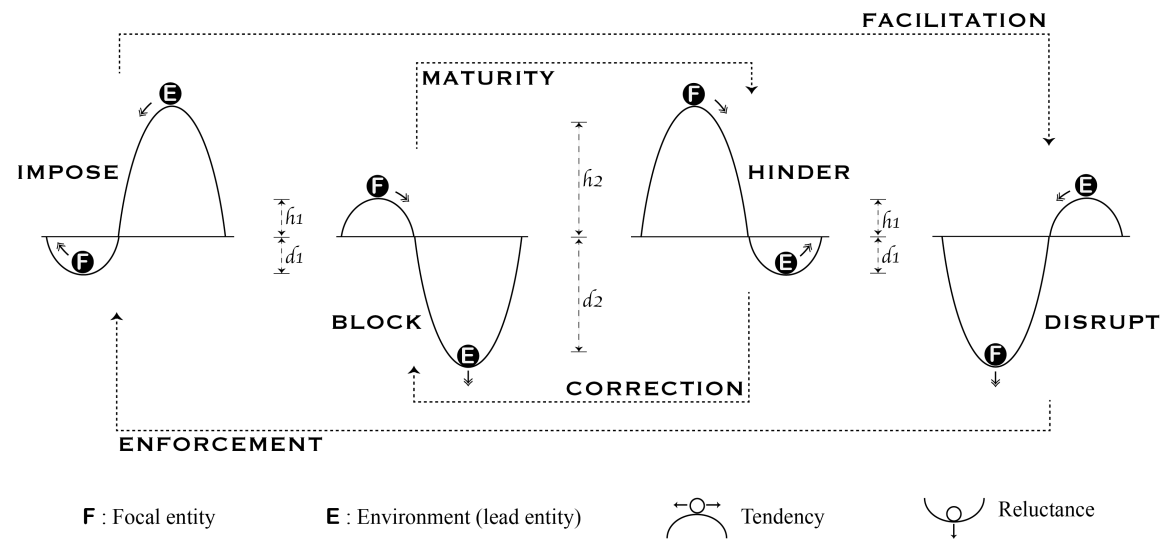

Figure 7: Modeling change as a transition between two force-dynamic patterns

point to reason about the cause-and-effect relationships that may have influenced the customer's experience of the service. It, in itself, does not provide any means, conceptual or otherwise, to reason the customer's judgment of the service. In the past, there has been some effort to emphasize the affective nature of experience by enhancing the traditional blueprint format with dedicated visual icons for representing the emotional state of the customer [31]. This certainly enhances the visual appeal of the blueprint format making it more thought provoking for the users, though it continues to remain propositional in nature - the difference being that textual representation has made way for visual icons.

The remaining part of this paper is structured in two parts. Section 2 describes the force-dynamic apparatus proposed for activating the situated-andembodied approach to service-design. Section 3 builds on the mixed-mode commuting example and demonstrates how the force-dynamic patterns can be used to specify a service.

\section{Force-dynamic Patterns}

Force-dynamics is the study of interaction between entities with respect to the forces that they exert and undergo. The concept of force has its origin in natural sciences, where it is defined as the "influence that causes an object [with mass] to undergo a certain change, either concerning its movement, direction, or geometrical construction" [32]. In the context of human-oriented problem solving, the more relevant force factors are the ones originating in the psychological and sociological domains - e.g. goals, beliefs, desires and intentions [33]. Linguistic expressions provide a good source for identifying such types of force factors. As described in [27], linguistic evidence suggests human body is perceptive of all those interactions with the external world, which can be modeled in terms of "a stronger force opposing a weaker force head on, with all-or-none conditions". This is reflected in the lexicon of English language, which not only includes expressions like 'despite' and 'although' that suggest observable state change, but also 'let' and 'hindrance' that convey the presence of some opposing force even though the opposition is not strong enough to bring about any observable state change. Perception, though, differs from judgment [34]. The adopter's appreciation of a service is a judgment that emerges by contrasting some perception of the adopter before the adoption of the service and the perception after the adoption of the service. From a service design perspective, this differential is the change the service intends to implement. In the context of problem solving, the differential can be modeled as an ordered-pair of force-dynamic patterns - the first one corresponds to the challenge that the adopter of the service faces and the second corresponds to the response by the service. Thus, given the expression of experience, i.e. the value proposition, we identify the forces influencing this judgment, and the entities that are responsible for exerting these forces.

\subsection{Visual Semantics}

Figure 7 presents the force-dynamic patterns considered in this work. The focal-entity $(\mathbf{F})$ refers to the entity that is the subject of attention, the environment-lead-entity (E) refers to the other most relevant entity in the situation that the pattern models. Since the focus is on change, the force-factors considered in this work are expressed either in terms of reluctance to change or tendency to change. In the context of human-oriented inquiry, this distinction can be attributed to the goal-oriented behavior of the subject [35]. To facilitate the visual apprehension [36] of these patterns, we employ the peak-and-trough metaphor, and assign a set of visual semantics [37], which conveys the meaning of these force-dynamic 


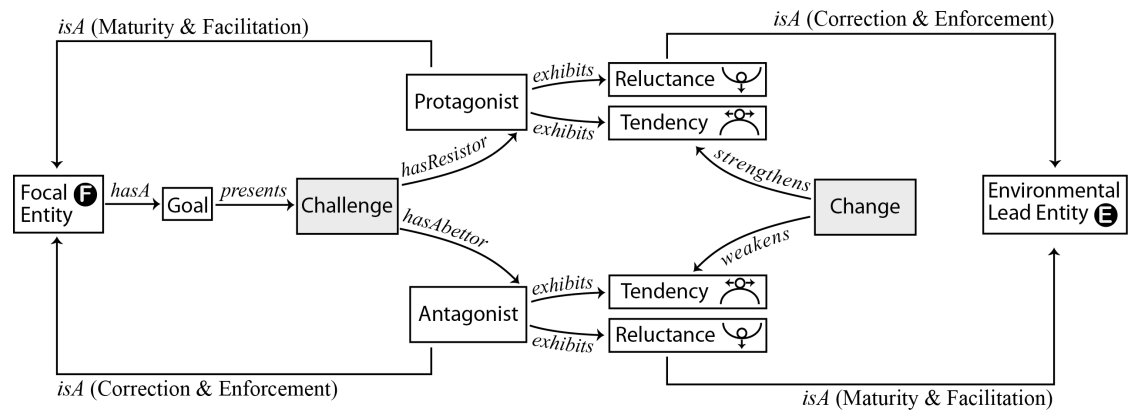

Figure 8: The ontology underlying value frames

patterns through commonly encountered visual patterns, e.g. a rock rolling down a hill or an instance of marble running down a wooden chute in a game of marble-run. The basic idea is that every action has a normative core [38]. Depending on the situation, an action may manifest itself overtly - in terms of achieving some new state, or inertly in terms of maintaining an existing state. We invoke the peak-andtrough metaphor to convey these overt and inert manifestations of a norm. The visual of a marble perched on an elevated chute is used to simulate the overt expression of a norm as the tendency of the marble to roll down the chute and bring about the desired change by displacing other marbles that come in its way. The height of the peak represents the strength with which this tendency is being pursued. The visual of a marble in a trough is used to simulate the inert expression of a norm as the reluctance of the marble to get displaced. The depth of the trough represents the strength with which this reluctance is being held.

The semantics of the different force-dynamic patterns is conveyed visually by interchanging the positions of $\mathbf{F}$ and $\mathbf{E}$ between being held in the trough or perched on the peak, and varying the height of the peak and the depth of the trough. The E perched on a peak high enough to displace the $\mathbf{F}$ held in a trough $\left(\hbar_{2}>\delta_{1}\right)$ represents a situation where the resultant force experienced by the focal-entity is one of imposition the IMPOSE pattern. On the other hand, the E perched on a peak not high enough to displace the $F$ held in a deep trough $\left(\zeta_{1}<\delta_{2}\right)$ represents a situation where the resultant force experienced by the focal-entity is one of disruption - the DIsRUPT pattern. The visual semantics of the force-dynamic patterns - HINDER and BLOCK can also be interpreted in a similar manner by interchanging the positions of $\mathbf{F}$ and $\mathbf{E}$.

\subsection{Value Frames}

The insight that this work provides is that the change that the service should implement to realize a given value-proposition, can be characterized in terms of the nature of the underlying challenge that the service helps the adopter overcome, and the way it does so. As shown in Figure 8, we model the challenge that the focal-entity reveals in relation to the valueproposition as having a protagonist and an antagonist. The protagonist here is the entity that is identified as trying to resist the challenge, while antagonist is the entity that is identified as abetting the challenge. Value is created when the challenge is addressed by bringing about some change. The basic assumption here is that the consumption of a service-feature, which brings about change, acts on one entity at a time. It could bring about change at the focal-entity or at the environment-lead-entity. There is no loss of generality due to this assumption. In fact, we believe this is useful in untangling feature bundles by clearly specifying the context, i.e. the underlying challenge, to which the feature is relevant and also what change it brings about to realize the proposed value. In case there are multiple challenges wedded in one value proposition, we suggest using techniques like FCA (Formal Concept Analysis) [39], to untangle them.
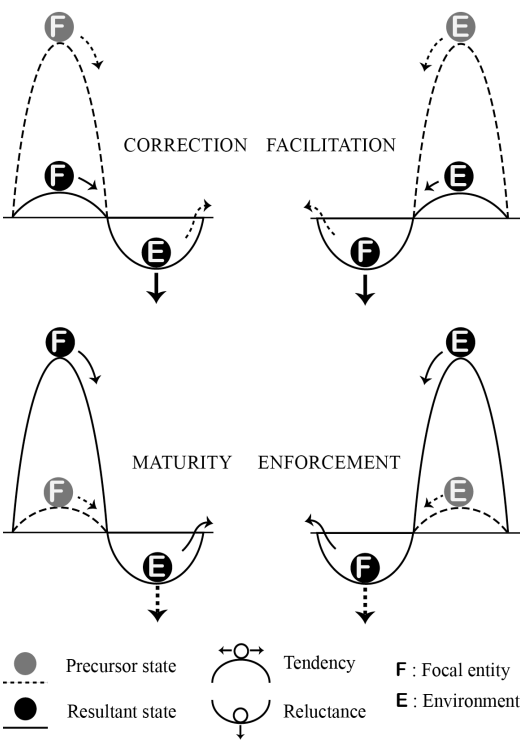

Figure 9: The four Value Frames 
The constraint that we place on change is that it only acts on the entity, which demonstrates an active tendency towards goal pursuit. Reluctance here represents normative behavior, which by definition stays the same across different situations. The new tendency is either stronger or weaker than the reluctance of the other entity. This assumption limits the number of valid transitions to the following ordered-pair of force-dynamic patterns: (IMPOSE, DISRUPT) - the FACILITATION FRAME, (DISRUPT, IMPOSE) - the ENFORCEMENT FRAME, (HINDER, BLOCK) - the CORRECTION FRAME and (BLOCK, allow) - the Maturity frame. These transitions are shown in Figure 7. Figure 9 provides a concise representation of the same transitions.

To ensure that the ordered pair is able to convey the complete information related to the change that is required to realize the value-proposition, we represent it as a Frame. Frame is an approach to organizing information that represents a cohesive region in conceptual space [28]. It includes information on all aspects of a situation that may be required to recreate the imagistic character that the conceptualization entails. In addition to the two force-dynamic patterns, value-frame also includes the context that lends the frame a semantic orientation, and also includes propositional claims of the service-feature and the value that it claims to create. Further, it also includes attribute-value pairs disclosing the identity of the focalentity and the identity of the most prominent entity from amongst the group of entities represented in the environment. The information structure of the value frame is shown in Figure 10.

\section{The Facilitation Frame}

The service semantics reified in the Facilitation frame is one where value is created by virtue of the servicefeature weakening the environments' force that otherwise was strong enough to bring about change at the focal-entity. With the adoption of the service, the environmental force resisting the norm secedes so as to facilitate the focal-entity in retaining its original state. In this situation, the patient role is undertaken by the lead entity in the environment.

\section{The Enforcement Frame}

The service semantics reified in the Enforcement frame is one where value is created by virtue of the servicefeature strengthening the tendency of the environment to bring about some change at the focal-entity. In the precursor state, the environmental force was not strong enough to change the behavior of the focal-entity, which was reluctant to give up a behavior that was hindering the value creation. By strengthening the

\begin{tabular}{|l|l|}
\hline \multicolumn{2}{|c|}{ <type of> VALUE FRA ME } \\
\hline FEATURE & < service-feature expressed as a proposition > \\
\hline VALUE & < service-value expressed as a proposition > \\
\hline CONTEXT & < challenge faced by the focal_entity > \\
\hline $\begin{array}{l}\text { FOCAL_ENTITY } \\
\text { entity who experiences the change > }\end{array}$ & $\begin{array}{l}\text { < the force exerted by the focal_entity > } \\
\text { abressed as either reluctance to some change, or tendency to bring }\end{array}$ \\
\hline $\begin{array}{l}\text { ENVIRONMENT_LEAD_ENTITY } \\
\text { the most relevant entity other than } \\
\text { the focal_entity > }\end{array}$ & $\begin{array}{l}\text { < the force exerted by the environment_lead_entity > } \\
\text { expressed as either reluctance to some change, or tendency to bring } \\
\text { about change }\end{array}$ \\
\hline $\begin{array}{l}\text { PATIENT } \\
\text { entity where change is introduced, } \\
\text { either the focalentity or the } \\
\text { environment_lead_entity > }\end{array}$ & $\begin{array}{l}\text { < the force exerted by the patient under the influence of the service > } \\
\text { expressed as tendency to bring about change }\end{array}$ \\
\hline
\end{tabular}

Figure 10: Information fields of Value Frame

environment, a well-meaning change is enforced on the focal-entity. In this situation too, the patient role is undertaken by the lead entity in the environment.

\section{The Correction Frame}

The service semantics reified in the Correction frame is one where value is created by virtue of the servicefeature weakening the focal-entity's pursuit of change, which otherwise was strong enough to overcome the resistance offered by the reluctance of the environment in accepting the change. In a sense, the adoption of the service corrects the behavior of the focal-entity to stop overpowering the environment, thereby creating value. In this situation, the patient role is undertaken by the focal-entity.

\section{The Maturity Frame}

The service semantics reified in the Maturity frame is one where value is created by virtue of the servicefeature strengthening the focal-entity's pursuit of change, which otherwise was blocked by virtue of the environment reluctance to accept change. In a sense, the adoption of the service helped the focal entity mature and exert greater pressure on the environment to change, thereby achieving a goal that brings it the desired value. In this situation too, the patient role is undertaken by the focal-entity.

\section{Mixed-mode Commuting Service Design}

We continue with the example of designing a foldablebike based mixed-mode commuting service. To recall, an initial version of the service system is depicted in Figure 1, and the associated feature-value matrix is captured in Figure 2. We assume the existence of some initial idea of the service that the service-designer tries to transform into a commercially meaningful offering. A value-frame based inquiry systematizes the design process by guiding the service-designer through the 


\begin{tabular}{|l|l|}
\multicolumn{2}{|c|}{ FRAME 1: MATURITY } \\
\hline FEATURE ( $\left.F_{1}\right)$ & ability to avoid traffic delays \\
\hline VALUE PRoPosition $\left(V_{1}\right)$ & increased likelihood to get to office on time \\
\hline CONTEXT & $\begin{array}{l}\text { to get to office } \\
\text { - the challenge of spending too much time in } \\
\text { commute }\end{array}$ \\
\hline $\begin{array}{l}\text { FoCAL_ENTITY :: Mixed-mode commuter } \\
\text { as a Commuter }\end{array}$ & tendency to get to office on time \\
\hline ENV_LEAD_ENTITY :: Co-commuter & $\begin{array}{l}\text { reluctance to give up personal conveyance for } \\
\text { office commute to reduce rush-hour traffic }\end{array}$ \\
\hline $\begin{array}{l}\text { PATIENT :: Mixed-mode Commuter as a } \\
\text { Passenger }\end{array}$ & $\begin{array}{l}\text { lwitching to public transport helps avoid } \\
\text { traffic delays }\end{array}$ \\
\hline
\end{tabular}

\begin{tabular}{|l|l|}
\multicolumn{2}{|c|}{ FRAME 5: ENFORCEMENT } \\
\hline FEATURE ( $\left.F_{5}\right)$ & helps enhance professional profile on the web \\
\hline VALUE PRoposition (V) & possibility to fast track career progression \\
\hline CoNTEXT & $\begin{array}{l}\text { to progress in career } \\
\text { - the challenge of establishing oneself as a } \\
\text { punctual employee }\end{array}$ \\
\hline $\begin{array}{l}\text { FocAL_ENTITY :: Mixed-mode Commuter } \\
\text { as a Career Professional }\end{array}$ & $\begin{array}{l}\text { reluctance to publicize oneself's punctuality } \\
\text { to work }\end{array}$ \\
\hline $\begin{array}{l}\text { ENV_LEAD_ENTITY :: Professional } \\
\text { Social Network as a Publisher }\end{array}$ & $\begin{array}{l}\text { tendency to request creating punctuality } \\
\text { profile }\end{array}$ \\
\hline $\begin{array}{l}\text { PATIENT :: Professional Social } \\
\text { Network as an Information } \\
\text { Aggregator }\end{array}$ & $\begin{array}{l}\text { provides an IT interface to automatically } \\
\text { gather data from corporate networks on } \\
\text { arrival and departure time of office workers }\end{array}$ \\
\hline
\end{tabular}

\begin{tabular}{|l|l|}
\hline \multicolumn{2}{|c|}{ FRAME 2: FACILITATION } \\
\hline FEATURE $\left(\mathrm{F}_{2}\right)$ & $\begin{array}{l}\text { ability to avoid travel with oversized } \\
\text { objects }\end{array}$ \\
\hline VALUE PROPOSITION $\left(\mathrm{V}_{2}\right)$ & $\begin{array}{l}\text { increased likelihood to avoid inconvenience } \\
\text { to fellow passengers }\end{array}$ \\
\hline CoNTEXT & $\begin{array}{l}\text { to comply with civic norms } \\
\text { - the challenge of avoid causing injury to } \\
\text { fellow passengers from the bike }\end{array}$ \\
\hline $\begin{array}{l}\text { FoCAL_ENTITY :: Mixed-mode Commuter } \\
\text { as a Co-passenger }\end{array}$ & $\begin{array}{l}\text { reluctance to travel with baggage that causes } \\
\text { inconvenience to fellow passengers }\end{array}$ \\
\hline $\begin{array}{l}\text { ENV_LEAD_ENTITY:: Bike } \\
\text { Manufacturer as a Rigid-frame-bike } \\
\text { Manufacturer }\end{array}$ & tendency to manufacture rigid-design bikes \\
\hline $\begin{array}{l}\text { PATIENT :: Bike Manufacturer as a } \\
\text { foldable-frame-bike Manufacturer }\end{array}$ & $\begin{array}{l}\text { Bike Manufacturer provide collapsible frame- } \\
\text { design that helps avoid travel with } \\
\text { oversized objects }\end{array}$ \\
\hline
\end{tabular}

\begin{tabular}{|l|l|}
\hline \multicolumn{2}{|c|}{ FRAME 6: FACILITATION } \\
\hline FEATURE ( $\left.\mathrm{F}_{6}\right)$ & $\begin{array}{l}\text { helps provide next-to-each-other seating for } \\
\text { friends }\end{array}$ \\
\hline VALUE PROPOSITION ( $\left.\mathrm{V}_{6}\right)$ & potential to earn greater social recognition \\
\hline CoNTEXT & $\begin{array}{l}\text { to stay socially active } \\
\text { - the challenge of reduced social }\end{array}$ \\
\hline $\begin{array}{l}\text { FoCAL_ENTITY :: Mixed-mode commuter } \\
\text { as a Co-passenger }\end{array}$ & reluctance to stay away from personal baggage \\
\hline $\begin{array}{l}\text { ENV_LEAD_ENTITY :: Bike } \\
\text { Manufacturer as a traditional } \\
\text { designer }\end{array}$ & $\begin{array}{l}\text { tendency to think of bike as a liability to } \\
\text { carry }\end{array}$ \\
\hline $\begin{array}{l}\text { PATIENT :: Bike Manufacturer as an } \\
\text { innovative designer }\end{array}$ & $\begin{array}{l}\text { new design of bikes provides seating for two } \\
\text { when folded }\end{array}$ \\
\hline
\end{tabular}

\begin{tabular}{|c|c|}
\hline \multicolumn{2}{|c|}{ FRAME 3: MATURITY } \\
\hline FEATURE $\left(\mathrm{F}_{3}\right)$ & ability to reduce cost of travel \\
\hline VALUe Proposition $\left(\mathrm{V}_{3}\right)$ & $\begin{array}{l}\text { increased likelihood to spend more on } \\
\text { household purchases }\end{array}$ \\
\hline CONTEXT & $\begin{array}{l}\text { to manage household budget } \\
\text { - the challenge of generating additional } \\
\text { support for household purchases }\end{array}$ \\
\hline $\begin{array}{l}\text { FOCAL_ENTITY :: Mixed-mode Commuter } \\
\text { as a Home Maker }\end{array}$ & tendency to increase income by cutting costs \\
\hline ENV_LEAD_ENTITY :: Family & reluctance to reduce household demands \\
\hline $\begin{array}{l}\text { PATIENT :: Mixed-mode Commuter as a } \\
\text { Payee }\end{array}$ & $\begin{array}{l}\text { reduced cost of travel by train helps saving } \\
\text { cost. }\end{array}$ \\
\hline
\end{tabular}

\begin{tabular}{|l|l|}
\hline \multicolumn{2}{|c|}{ FRAME 7: FACILITATION } \\
\hline FEATURE ( $\left.F_{7}\right)$ & provides access to retail discounts \\
\hline VALUE PROPOSITION (V 7$)$ & potential to increase household purchases \\
\hline CoNTEXT & $\begin{array}{l}\text { to increase buying capacity } \\
\text { - the challenge of meeting household needs }\end{array}$ \\
\hline $\begin{array}{l}\text { FoCAL_ENTITY :: Mixed-mode Commuter } \\
\text { as a Retail Customer }\end{array}$ & reluctance to spend beyond monthly budget \\
\hline $\begin{array}{l}\text { ENV_LEAD_ENTITY :: Retail Award } \\
\text { Program as Loyalty Promoter }\end{array}$ & $\begin{array}{l}\text { tendency to provide special offers to } \\
\text { qualified customers }\end{array}$ \\
\hline $\begin{array}{l}\text { PATIENT :: Retail Award Program as } \\
\text { a Fitness Promoter }\end{array}$ & $\begin{array}{l}\text { include mixed-mode commuters in their award } \\
\text { program for promoting lifestyle trendsetters } \\
\text { footfall }\end{array}$ \\
\hline
\end{tabular}

\begin{tabular}{|l|l|}
\hline \multicolumn{2}{|c|}{ FRAME 4: CORRECTION } \\
\hline FEATURE ( $\left.F_{4}\right)$ & ability to perform physical workout \\
\hline VALUE Proposition (V 4$)$ & $\begin{array}{l}\text { increased likelihood to reduce health } \\
\text { problems }\end{array}$ \\
\hline CONTEXT & $\begin{array}{l}\text { to stay healthy } \\
\text { - the challenge of finding time to do } \\
\text { physical workout }\end{array}$ \\
\hline $\begin{array}{l}\text { FoCAL_ENTITY :: Mixed-mode Commuter } \\
\text { as a Health Conscious Person }\end{array}$ & $\begin{array}{l}\text { tendency to not allocate separate time for } \\
\text { physical fitness }\end{array}$ \\
\hline ENV_LEAD_ENTITY :: Doctors & $\begin{array}{l}\text { reluctance to consider physically unfit } \\
\text { people as healthy }\end{array}$ \\
\hline $\begin{array}{l}\text { PATIENT :: Mixed-mode Commuter as a a } \\
\text { Bike rider }\end{array}$ & $\begin{array}{l}\text { riding the bike requires the adopter } \\
\text { undertake physical workout that helps reduce } \\
\text { health problems }\end{array}$ \\
\hline
\end{tabular}

\begin{tabular}{|l|l|}
\hline \multicolumn{2}{|c|}{ FRAME 8: MATURITY } \\
\hline FEATURE ( $F_{8}$ ) & $\begin{array}{l}\text { helps provide easy access to verifiable data } \\
\text { on physical workout }\end{array}$ \\
\hline VALUE PROPOSITION ( $\left.V_{8}\right)$ & potential to save money \\
\hline CoNTEXT & $\begin{array}{l}\text { to reduce healthcare costs } \\
\text { - the challenge of high health care costs }\end{array}$ \\
\hline $\begin{array}{l}\text { FoCAL_ENTITY :: Mixed-mode Commuter } \\
\text { as a Healthcare Insuree }\end{array}$ & $\begin{array}{l}\text { pay higher insurance premiums due to lack of } \\
\text { evidence of using bike }\end{array}$ \\
\hline $\begin{array}{l}\text { ENV_LEAD_ENTITY :: Insurance } \\
\text { Company }\end{array}$ & $\begin{array}{l}\text { reluctance to reduce insurance premiums for } \\
\text { people with no evidence to support claims of } \\
\text { healthy lifestyle }\end{array}$ \\
\hline $\begin{array}{l}\text { PATIENT :: Mixed-mode Commuter as } \\
\text { an Information Generator }\end{array}$ & $\begin{array}{l}\text { lower insurance premiums by providing } \\
\text { insurance companies easy access to verifiable } \\
\text { data on user's physical workout }\end{array}$ \\
\hline
\end{tabular}

Figure 11: Value frames for the mixed-mode commuting+ service

possibility space in an interactive manner. It first tries to ensure the well-formedness of the initially identified value-propositions by adopting a shift-to-the-center strategy. The idea is to articulate value-propositions while focusing on the being of the adopter and not any specific role that she might be undertaking. The value- 


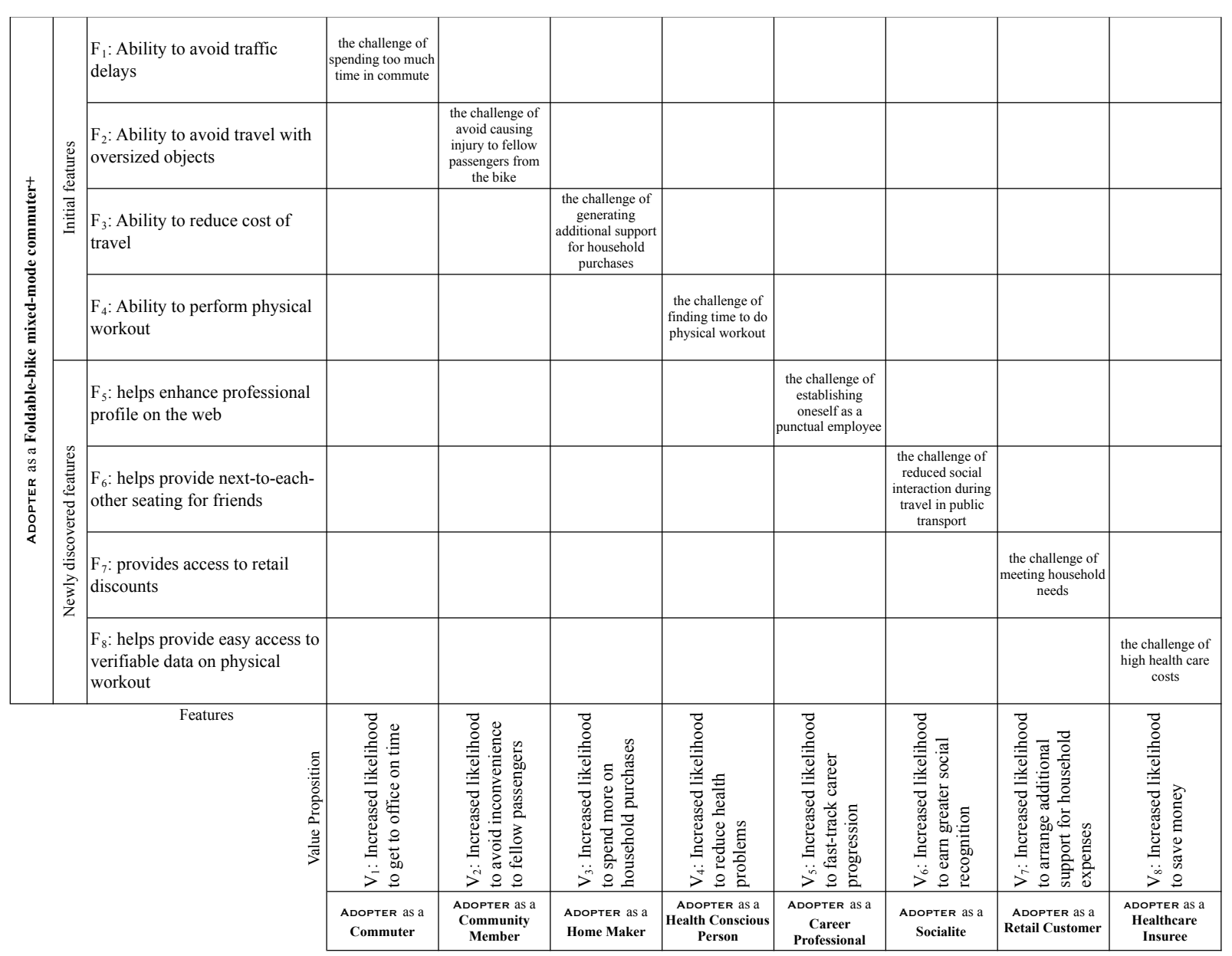

Figure 12: Feature-value matrix for mixed-mode commuting+ service

propositions $\mathrm{V}_{5}-\mathrm{V}_{8}$ are the result of applying this strategy on the initial value propositions, $V_{1}-V_{4}$. For example, the question that generates $\mathrm{V}_{4}$ from $\mathrm{V}_{1}$ is: What benefit does the increased likelihood to get to office on time provides to the adopter? One answer could be the increased likelihood to fast track career progression. Figure 12, documents the feature valuematrix for the revised service.

The next step is to identify the value-frame most appropriate for each value proposition. Systematically analyzing the cause-and-effect underlying the valueproposition helps identify the precise change required to invoke the appreciation that the value-proposition expresses. As indicated in the model presented in Figure 6, for already identified feature-value pairs, value-frames can be seen as checking their alignment, i.e. a feature does bring about the change that the associated value-proposition claims, while for newly surfaced value-propositions it helps identify the feature and the entities required to implement that feature. The process of frame selection and population followed the ontology presented in Figure 8. The resulting frames are documented in Figure 11. It is important to note that value-frames encourage the designer to consider multiple viewpoints while selecting the most appropriate frame to narrate the underlying situation. The value-frame based approach to specifying the mixed-mode commuting service helped identify additional features (features $\mathrm{F}_{5}-\mathrm{F}_{8}$ in Figure 12), and the entities required to implement these features (refer to the patient field of value-frames in Figure 11 and the updated service system in Figure 4).

\section{Conclusion}

As the field of Service Science matures, it will have to develop a more normative body of knowledge, one that the service designer can use in her day-to-day practice. Given the focus of services on specifying solutions that create value for the adopter, it is important that service scientists acknowledge the challenges that arise due to the social and bodily being of the human-adopter. Towards this end, we provide a set of modeling constructs that the service-designer can use to surface 
the true semantics of a service, thereby specifying much more accurately the features to be included in the service, and the partners required to implement them.

\section{References}

[1] S. L. Vargo and R. F. Lusch, "Evolving to a New Dominant Logic for Marketing," Journal of Marketing, vol. 68, pp. 1-17, 2004/01/01 2004

[2] R. F. Lusch, S. L. Vargo, and G. Wessels, "Toward a conceptual foundation for service science: contributions from service-dominant logic," IBM Syst. J., vol. 47, pp. 5-13, 2008.

[3] C. Lovelock, "Classifying Services to Gain Strategic Marketing Insights," The Journal of Marketing, vol. 47, pp. 9-20, 1983 .

[4] H. Chesbrough and J. Spohrer, "A research manifesto for services science," Commun. ACM, vol. 49, pp. 35-40, 2006.

[5] Pine and J. H. Gilmore, "The Experience Economy: Work Is Theatre \& Every Business a Stage," 1999.

[6] J. Spohrer, P. P. Maglio, J. Bailey, and D. Gruhl, "Steps Toward a Science of Service Systems," Computer, vol. 40, pp. 71-77, 2007.

[7] P. P. Maglio, S. Srinivasan, J. T. Kreulen, and J. Spohrer, "Service systems, service scientists, SSME, and innovation," Commun. ACM, vol. 49, pp. 81-85, 2006.

[8] K. J. Rohlfing, M. Rehm, and K. U. Goecke. (2003, Situatedness: The Interplay between Context(s) and Situation. Journal of Cognition and Culture 3, 132-156.

[9] G. Vickers, The Art of Judgment: A study of Policy Making, 1995.

[10] E. v. Hippel, "Sticky information and the locus of problem solving: implications for innovation," Manage. Sci., vol. 40, pp. 429-439, 1994.

[11] J. Forlizzi, "All look same?: a comparison of experience design and service design," interactions, vol. 17, pp. 60-62, 2010.

[12] L. W. Barsalou, "Grounded Cognition: Past, Present, and Future," Topics in Cognitive Science, vol. 2, pp. 716-724, 2010.

[13] L. A. Suchman, Plans and situated actions: the problem of human-machine communication: Cambridge University Press, 1987.

[14] E. Rosch, "Principles of Categorization," in Cognition and Categorization, E. Roach and B. B. Lloyd, Eds., ed Hillsdale, NJ: Lawrence Erlbaum, 1978, pp. 27-48.

[15] B. Hjørland, "Concept theory," Journal of the American Society for Information Science and Technology, vol. 60, pp. 1519-1536, 2009.

[16] S. E. Palmer, "Fundamental aspects of cognitive representation," in Cognition and Categorization, E. Rosch and B. Lloyd, Eds., ed: Lawrence Erlbaum, 1978, pp. 259303.

[17] K. Koffa, Principles of Gestalt Psychology. London: Routledge \& Kegan Paul Ltd, 1935.

[18] M. Wilson, "Six Views of Embodied Cognition," Psychonomic Bulletin \& Review, vol. 9, pp. 625--636, 2002.

[19] F. Strack, L. Martin, and S. Stepper, "Inhibiting and facilitating conditions of the human smile: a nonobtrusive test of the facial feedback hypothesis," Journal of Personality and Social Psychology, vol. 54, p. 768, 1988.

[20] P. Niedenthal, L. Barsalou, P. Winkielman, S. KrauthGruber, and F. Ric, "Embodiment in Attitudes, Social Perception, and Emotion," Personality and Social Psychology Review, vol. 9, pp. 184-211, 2005.

[21] Wikipedia. Wikipedia definition of laughter yoga. Available: http://en.wikipedia.org/wiki/Laughter_Yoga

[22] W. Croft and D. A. Cruse, Cognitive Linguistics. Cambridge, UK: Cambridge University Press, 2004.

[23] G. Lakoff, Women, Fire, and Dangerous Things: University Of Chicago Press, 1990.

[24] S. Laurence and E. Margolis, "Concepts and Cognitive Science," in Concepts: Core Readings, E. Margolis and S. Laurence, Eds., ed: MIT, 1999.

[25] L. Talmy, Toward a cognitive semantics vol. 1. Cambridge, MA: MIT Press, 2000.

[26] A. Tarski, "The semantic conception of truth: And the foundations of semantics," Philosophy and Phenomenological Research, vol. 4, pp. 341-376, 1944.

[27] L. Talmy, "Force Dynamics in Language and Cognition," Cognitive Science, vol. 12, pp. 49-100, 1988.

[28] M. Minsky, "A Framework for Representing Knowledge," Massachusetts Institute of Technology 1974.

[29] G. L. Shostack, "Designing services that deliver," Harvard Business Review, pp. 133-139, 1984.

[30] M. Bitner, A. Ostrom, and F. Morgan, "Service Blueprinting: A Practical Technique for Service Innovation," 2007.

[31] S. L. Spraragen and C. Chan, "Service Blueprinting: When customer satisfaction numbers are not enough," presented at the International DMI Education Comference. Design Thinking: New Challenges for Designers, Managers and Organizations, Cergy-Pointoise, France, 2008.

[32] Wikipedia, "Wikipedia definition of force."

[33] M. Georgeff, B. Pell, M. Pollack, M. Tambe, and M. Wooldridge, "The Belief-Desire-Intention Model of Agency Intelligent Agents V: Agents Theories, Architectures, and Languages," in Intelligent Agents $V:$ Agents Theories, Architectures, and Languages. vol. 1555, J. Müller, A. Rao, and M. Singh, Eds., ed: Springer Berlin / Heidelberg, 1999, pp. 1-10.

[34] C. G. Jung, Psychological Types: Princeton University Press, 1976.

[35] E. L. Deci and R. M. Ryan, "The "What" and "Why" of Goal Pursuits: Human Needs and the Self-Determination of Behavior," Psychological Inquiry, vol. 11, pp. 227-268, 2000.

[36] D. Schon and G. Wiggins, "Kinds of seeing and their functions in designing," Design Studies, vol. 13, pp. 135-156, 1992.

[37] J. Gero and H. Jun, "Visual semantics emergence to support creative designing: a computational view," Department of Architectural and Design Science, The University of Sydney 1995.

[38] I. Ajzen, "The theory of planned behavior," Organizational Behavior and Human Decision Processes, vol. 50, pp. 179-211, 1991.

[39] U. Priss, "Formal concept analysis in information science," Annual Rev. Info. Sci $\mid \&$ Technol., vol. 40, pp. 521543, 2006. 